Firearms Training Based on the Development of Mental Processes. Pedagogiko-psihologicheskie $i$ mediko-biologicheskie problemy fizicheskoj kul tury` $i$ sporta = Pedagogico-pshycological and medico-

Подано: 30.05.2018 biological problems of physical cultury and sport. 2017; 12(2): 146-153. URL: http://www.journalscience.org/ru/article/803.html.

10.14526/01_2017_216 [In Russ., In Engl.].
DOI

Кузнецова Зинаида Михайловна - доктор педагогических наук, профессор, Федеральное государственное бюджетное образовательное учреждение высшего образования «Ульяновский государственньй педагогический университет имени И.Н. Ульянова», 432700, Россия, г. Ульяновск, площуадь 100-летия со дня рождения В.И. Ленина, дом 4, е-таil: kzm_diss@mail.ru

Рябчук Андрей Владимирович - кандидат биологических наук, дочент, полковник запаса, Федеральное государственное бюджетное образовательное учреждение высшего образования «Тюменский государственный университет», 625003, Россия, г. Тюмень, ул. Володарского,дом 6, e-mail: aryabchuk@bk.ru

Лабещенков Олег Викторович - старший преподаватель, Федеральное государственное казенное военное образовательное учреждение высшего образования «Тюменское высшее военно-инженерное командное училище (военный институт) имени мармала инженерных войск А.И. Прошлякова».

DOI 10.14526/02_2018_327

УДК 378; 372.8:796

ББК 74.58+74.267.5

\title{
МЕТОДИКА ПОВЫШЕНИЯ УРОВНЯ ПРОФЕССИОНАЛЬНОЙ ПОДГОТОВКИ БУДУЩИХ УЧИТЕЛЕЙ ФИЗИЧЕСКОЙ КУЛЬТУРЫ В УСЛОВИЯХ ЛЕТНЕГО ОЗДОРОВИТЕЛЬНОГО ЛАГЕРЯ
}

\author{
Шакурова Л. Ф. ${ }^{1}$ \\ ${ }^{1}$ ФГБОУ ВО «Ульяновский государственный педагогический университет имени И.Н. \\ Ульянова» \\ Россия, г. Ульяновск
}

\begin{abstract}
Аннотация. Летний оздоровительный загородный лагерь, как правило, располагается рядом с лесным массивом, в непосредственной близости к водоему, что создает условия для эффективного использования естественных сил природы; в совокупности с физическими упражнениями это обеспечивает мощзный оздоровительный эфффект. Методы исследования: анализ и систематизачия научно-методической литературы, педагогический эксперимент, тестирование; разработка критериев оиенки степени сформированности уровня профессиональной подготовленности будущих учителей физической культурь, статистическая обработка данных. Материаль. $B$ статье рассматривается эффективность использования оздоровительных возможностей летних оздоровительных загородных лагерей, что в значительной мере определяется уровнем профессиональной подготовки будущих учителей. Это свидетельствует о необходимости обеспечения теоретической, методической и практической готовности студентов факультета физической культуры и спорта к выявлению и реализации творческого потенциала по использованию разнообразных форм занятий физическими упражнениями в сочетании с
\end{abstract}


естественныли природными условиями: чистого воздуха, дозированного ультрафиолетового излучения, а также водных процедур для решения задач укрепления здоровья детей и подростков, повышения их умственной и физической работоспособности, формирования потребности в систематическом воздействии физической нагрузки. Результаты. Приводится характеристика основных естественных локомоций, использование которых в условиях летнего лагеря способствует формированию интереса к различныл формам и средствам физической культуры, усвоению рациональной индивидуальной техники выполнения различных видов ходьбы и бега, что существенно увеличивает объем двигательной активности, формирует потребность в использовании физических упражнений как средства формирования «чувства мылиечной радости». Заключение. Разработанная методика совершенствования профессиональной подготовки будуших учителей физического воспитания обеспечивает формирование навыков творческого использования разнообразных необычных форм физического воспитания, обусловленных особенностями и возможностями летнего оздоровительного лагеря, позволяющего строить процеесс оздоровления отдыхающчих детей с учетом мощчного воздействия естественных факторов природы.

Ключевые слова: летний оздоровительный лагерь, методика совершенствования профессиональной подготовки будущих учителей физического воспитания.

Для цитирования: Шакурова Л.Ф. Методика повышения уровня профессиональной подготовки будущих учителей физической культуры в условиях летнего оздоровительного лагеря. Педагогико-психологические и медико-биологические проблемь физической культуры u cnopma. 2018; 13(2): 205-214. DOI 10.14526/02_2018_327

\title{
METHODOLOGY OF THE FUTURE PHYSICAL CULTURE TEACHERS PROFESSIONAL TRAINING LEVEL INCREASE IN TERMS OF SUMMER HEALTH CAMP
}

\author{
Shakurova L. F. ${ }^{1}$ \\ ${ }^{1}$ Federal State Budgetary Educational Establishment of Higher Education "Ulyanovsk State \\ Pedagogical University Named After I.N. Ulyanov" \\ Russia, Ulyanovsk
}

Annotation. Summer health camp, as a rule, is situated close to forest area, close to water and it creates conditions for effective use of natural powers. Together with physical exercises it provides powerful health improving effect. Research methods: scientific-methodical literature analysis and systematization, pedagogical experiment, testing; evaluation criteria creation for professional readiness level estimation among future physical culture teachers, statistical data handling. Materials. The article is about the effectiveness of health improving capacity use of summer health camps, which is mainly conditioned by professional readiness level of the future teachers. It proves the necessity to provide theoretical, methodical and practical readiness of physical culture and sport department students in order to reveal and realize creative potential of different forms of physical exercises use together with natural environmental conditions: fresh air, dosed ultraviolet radiation and also hydrotherapeutic procedures in order to solve the problems of children's and teen-agers' health improvement, their mental and physical working capacity increase, the need formation for systematic influence of physical load. Results. The characteristic of the main natural locomotions are presented, the use of which in terms of summer camp provides interest formation in different physical culture forms and means, individual rational techniques of different kinds of walking and running mastering, which increases considerably the volume of motor activity, forms need for physical exercises use as the means of "sense of muscle joy" formation. Conclusion. The created methodology of professional training improvement of the future physical culture teachers 
provides the skills formation of a creative use of different unusual forms of physical upbringing, conditioned by the peculiarities and capacities of summer health camp, which helps to organize the process of health improvement of children, taking into account powerful influence of natural factors of environment.

Keywords: summer health camp, methodology of professional training development among future physical culture teachers.

For citations: Shakurova L.F Methodology of the future physical culture teachers professional training level increase in terms of summer health camp. The Russian Journal of Physical Education and Sport (Pedagogico-Phycological and Medico-Biological Problems of Physical Culture and Sports). 2018; 13(2):205-214. DOI 10.14526/02_2018_327

\section{ВВЕДЕНИЕ}

В настоящее время в государственной системе образования РФ происходят значительные структурносодержательные и функциональные изменения, обусловленные современными политическими, идеологическими и социальными требованиями к выпускникам общеобразовательной и высшей школы. Основной задачей образования является разностороннее развитие личности, способной адаптироваться к новым условиям жизни, усваивать из большого объема информации наиболее актуальную, способствующую раскрытию духовнонравственной, интеллектуальной, психологической индивидуальности личности. Особое место в образовательном процессе принадлежит физической культуре - общеобразовательному предмету, направленному на совершенствование биологического, психологического и социального аспекта жизнедеятельности учащихся. Разнообразные формы, средства и методы физического воспитания должны быть направлены на выявление двигательного потенциала ребенка, его гармонизацию. По мнению В. К. Бальсевича, 2007; С.И. Захарова, 2008; В. И. Столярова, 2009; Л. Д. Назаренко, 2003, 2014, главной целью физического воспитания детей школьного возраста является формирование культуры здоровья. Однако сложность реализации положений данной педагогической концепции заключается в неготовности значительной части учителей физической культуры к практической деятельности в заданном направлении. Л.И. Лубышева, 2006, отмечая негативные тенденции в состоянии здоровья младших школьников, считает, что, несмотря на созданные в большинстве образовательных школ нормальные условия для физического воспитания, удовлетворительный уровень профессиональной подготовленности учителей физической культуры, функциональные показатели учащихся ухудшаются. Результаты исследований Л.Д. Назаренко, Е.А. Анисимовой, 2003, 2015; В.К. Бальсевича, 2007; С.Д. Неверковича, 2010; 3.М. Кузнецовой, 2011; Л.И. Костюниной, 2014 и др. свидетельствуют о низком уровне физической подготовленности и физического развития учащихся; значительном ухудшении состояния здоровья; снижении мотивации и интереса к занятиям физическими упражнениями. Анализ специальной литературы показал, что ученые в сфере физической культуры и спорта предлагают различные подходы к совершенствованию системы физического воспитания в школе, такие как организация занятий школьников по их спортивным предпочтениям $[5,6]$; оптимизация школьного процесса физического воспитания путем внедрения самобытных средств $[11,12]$; реализация педагогической концепции формирования культуры здоровья [7]; организация педагогических условий сохранения здоровья учащихся в образовательном пространстве школы и др. [2, 10].

Целью данной работы является теоретическое и экспериментальное обоснование совершенствования 
профессиональной подготовки учителей физической культуры в условиях летних оздоровительных лагерей.

Задачи: 1. Выявить особенности организации физкультурнооздоровительных и спортивно-массовых мероприятий в летнем оздоровительном лагере и степень готовности студентов факультета физической культуры и спорта к их проведению.

2. Разработать методику совершенствования профессиональной подготовки будущих учителей на основе реализации оздоровительной и эстетической функций физической культуры и спорта, проверить ее эффективность в процессе педагогического эксперимента.

\section{МАТЕРИАЛЫ И МЕТОДЫ}

Отношение детей и подростков к школьной физической культуре в значительной мере определяется личностью и профессионализмом учителя. Удовлетворенность занятиями физическими упражнениями - проблема психологическая (учет мотивов, потребностей, интересов, характера взаимоотношений между педагогом и учениками); педагогическая (выбор средств и методов обучения, способов организации занимающихся, оценка их деятельности); физиологическая (учет механизма адаптации к физической нагрузке, видам физических упражнений, постепенность увеличения объема и интенсивности тренировочной нагрузки) и социальная (улучшение имиджа, социального статуса). Исследования С.И. Захарова, 2008, свидетельствуют об отсутствии интереса школьников к урокам физической культуры из-за их низкой эмоциональности, однообразия двигательных заданий. По мнению Л.И. Лубышевой, 2006, урок физической культуры в школе должен рассматриваться как интегративный образовательный предмет, влияющий на формирование интеллектуальной, биологической, психологической и социальной сущности учащегося. Разнообразные формы физического воспитания, адекватные средства, высокоэстетичные физические упражнения, вариативность способов их выполнения, систематическая оптимальная мышечная нагрузка делают физическую культуру значимым компонентом личностного развития каждого школьника. Это, по мнению авторов, предъявляет высокие требования к профессиональной подготовке учителя физической культуры, уровень которой не соответствует требованиям настоящего времени.

В Законе РФ «Об образовании» (2012 г.), «Концепции долгосрочного социально-экономического развития на период до 2020 года», «Национальной доктрине развития образования РФ до 2025 года» сформулировано одно из основных требований к государственной системе образования: формирование духовно-нравственной личности, ориентированной на здоровый образ жизни; подчеркивается, что главной задачей образования является воспитание ответственного отношения к своему здоровью как высшей социальной ценности. Решение этой сложной задачи связано с необходимостью существенного повышения профессиональной подготовки учителя физической культуры, призванного заложить основы глубокого понимания значимости систематического использования физических упражнений как ведущего средства улучшения функционального состояния организма, показателей здоровья. Летний оздоровительный загородный лагерь располагает значительными возможностями для раскрытия творческого потенциала студентов факультета физической культуры и спорта, осознания роли и места физической культуры и спорта для формирования высоконравственной, социально-активной личности с развитым чувством ответственности за состояние своего здоровья, позволяющего внести собственный вклад в устойчивое экономическое и культурное развитие страны [10]. 
Особенностью летнего лагеря является возможность максимального использования естественных факторов природы, оказывающих оздоровительное воздействие на организм. Располагаясь в лесу, в непосредственной близости к водоемам, на свежем воздухе, лагерь обеспечивает максимальные возможности для использования целебных сил окружающей среды. В чистом воздухе, насыщенном ароматами трав, листьев разнообразных деревьев, кустарников, цветов, содержатся отрицательные электрические ионы, обладающие целебными свойствами. Воздействуя на нервные окончания открытых участков тела, воздух улучшает химический состав крови, улучшает кровообращение в кардиореспираторной и других физиологических системах, включая головной мозг.

Ультрафиолетовые солнечные лучи способствуют образованию витамина «А», «Д» и других необходимых организму веществ, обусловливают активизацию обмена веществ; повышают содержание эритроцитов и гемоглобина, что стимулирует умственную и физическую работоспособность, улучшают выносливость. При ежедневном воздействии водных процедур: обтирания, обливания, купания - увеличивается сопротивляемость к неблагоприятным изменениям температуры внешней среды. В летнее время года дети проводят максимальное количество времени на свежем воздухе в легкой одежде, позволяющей широко использовать природные факторы оздоровления, воздействие которых значительно усиливается с помощью физических упражнений. Это создает уникальные возможности для приобщения детей и подростков к физической культуре и спорту. Однако эффективность применяемых физических упражнений определяется уровнем профессиональной подготовки будущего учителя физической культуры, его способностью к творческому использованию ценностей физической культуры и спорта в сочетании с оздоровительными силами природы, применению новых необычных форм занятий, не доступных в условиях общеобразовательной школы.

\section{РЕЗУЛЬТАТЫ ИССЛЕДОВАНИЯ И ИХ ОБСУЖДЕНИЕ}

Нами была разработана методика формирования творческого подхода к выявлению и реализации способностей при организации физкультурнооздоровительной и спортивно-массовой деятельности детей и подростков в летнем оздоровительном лагере. Методика предусматривала формирование навыков обучения различным видам ходьбы и бега - естественных локомоций, оказывающих существенное воздействие на здоровье человека.

При ходьбе в работу вовлекается большое количество различных групп мышц, в которых происходит расширение мелких кровеносных сосудов, увеличивается их объем за счет мобилизации депонированной крови из печени, селезенки, подкожной клетчатки. Увеличение артериальной крови и ее циркуляция обеспечивают улучшение питания клеток тканей; усиливается вентиляция легких, становится более глубоким дыхание, что эффективнее насыщает организм кислородом; сердце работает в экономичном режиме. Однако ценность ходьбы как наиболее доступного средства физической культуры и спорта значительно снижается при формальном подходе к ее использованию, когда дети беспорядочным строем передвигаются по стадиону, не обращая внимания на положение туловища, головы, верхних конечностей, точность пространственновременных и пространственно-силовых параметров шагов.

При разработке нашей методики обучения рациональной ходьбе мы учитывали особенности летнего оздоровительного лагеря и возможность эффективного использования естественных сил природы: воздуха, солнечных лучей и воды. Дети выполняли 
различные виды ходьбы по внешнему периметру территории лагеря, где была подготовлена специальная пешеходная тропа. По всей длине тропы флажками разного цвета были обозначены участки, по которым следует передвигаться разными способами: от красного флажка до голубого - строевым шагом с четким взмахом рук, акцентированной постановкой ног; от голубого к зеленому занимающиеся перемещались выпадами с широкой амплитудой маховых движений рук; от зеленого флажка к оранжевому выполнялась ходьба в полуприседе, сохраняя прямое положение спины, глядя перед собой, руки на пояс; от оранжевого к фиолетовому флажку - отдыхающие шли правым боком вперед скрестным шагом, руки в стороны, удерживая красивую осанку и высокое положение головы и т.д. Учитель физической культуры контролировал движения каждого ребенка, делая соответствующие методические указания («дышать глубже»; «плечи развернуть», «из строя не выходить»; «сохраняем дистанцию» и др.) За лучшее выполнение видов ходьбы отряд награждался сладким призом. В лагере большое внимание уделялось обучению технике бега, физиологическому, доступному виду физических упражнений. Медленный бег создает комфортные условия для деятельности функциональных систем. Во время бега улучшается кровообращение, нормализируется артериальное давление; происходят положительные гормональные сдвиги в организме: увеличивается содержание в крови особого фермента, предотвращаюего возникновение атеросклероза. Рациональное дыхание во время бега выполняет функции массажа легких; прыжкообразный бег и бег с высоким подниманием бедра способствует укреплению мышц брюшного пресса. Однако универсальное, положительное воздействие бега на организм достигается при технически правильном выполнении беговых шагов.
Разработанная нами методика формирования творческого подхода к организации физкультурнооздоровительной и спортивно-массовой работы в летнем лагере предусматривала использование различных способов выполнения беговых упражнений:

- в колонне по одному, при сохранении дистанции три шага;

- в колонне по два, четыре и шесть человек с заданным интервалом;

а также видов беговых шагов:

- свободный бег;

- бег с захлестом голени назад;

- семенящий бег;

бедра;

- бег с высоким подниманием

- прыжкообразный бег.

Большое внимание уделялось согласованности движений верхних и нижних конечностей; снижению амплитуды колебательных движений тела в передне-заднем и боковом направлении. Для совершенствования индивидуальной техники беговых шагов использовались: специальные разметки с целью контроля длины шага; коридоры (на шесты, расположенные в начале и в конце беговой дорожки, натягивались шнуры на высоте плечевого пояса, ограничивающие амплитуду колебаний тела в боковом направлении и др.).

Спортивные соревнования проводились не только на скорость пробегания дистанции, но и на технику беговых шагов, которая оценивалась по каждому виду. Оценка выставлялась по пятибалльной системе и входила в копилку команды. Победители получали сладкий общекомандный приз. Утренняя гимнастика проводилась в лагере только в сочетании с оздоровительным бегом. Выходя на утреннюю пробежку по специальной тропе, расположенной по внешнему периметру территории лагеря, дети в ходе бега должны были найти спрятанный на дорожке конверт с разновидностью упражнений утренней гимнастики: 
- «ежик» - комплекс коротких стилизованных отрывистых движений, требующих внимания и координации движений верхних и нижних конечностей;

- «колобок» - комплекс физических упражнений на небольшом куске ткани, включающий перекаты, физические упражнения, выполненные сидя и лежа, переходы из высоких положений в низкие и, наоборот;

- «лиса» - плавные, медленные, силовые и маховые движения.

Выбранный вид утренней гимнастики выполнялся на точность, красоту, выразительность движений. Лучший отряд получал право выбора подвижной или спортивной игры: городки, лапта, перетягивание каната, пионербол, стритбол и др. Утренняя зарядка завершалась обтиранием влажным полотенцем, приготовленным заранее. При проведении физкультурных и спортивных мероприятий участвовали судьи из числа детей, не занятых в данных формах, а также все воспитатели, получившие необходимый инструктаж перед началом состязаний.

Для проверки эффективности разработанной нами методики был проведен педагогический эксперимент, в котором приняли участие 39 студентов второго курса факультета физической культуры и спорта Ульяновского государственного педагогического университета им. И.Н. Ульянова. Были организованы две группы: контрольная (КГ) - 19 человек, и экспериментальная (ЭГ) - 20 человек. Перед началом педагогического эксперимента студентам было предложено провести несколько форм занятий физическими упражнениями: утреннюю гимнастику; подвижную или спортивную игру; спортивное соревнование по различным видам ходьбы и бега. Будущие учителя физической культуры предпочли следующие виды занятий:

I - комплекс упражнений для утренней зарядки, выполняемых стоя на месте. Различия в их проведении нашли свое отражение в расположении занимающихся: стоя в кругу; построении в две и четыре шеренги;

II - при выборе подвижной или спортивной игры будущие выпускники факультета физической культуры и спорта остановились на «пионерболе»;

III - соревнования по бегу проводились в двух видах: «веселые старты» и бег на 60м.

Организация и проведение данных форм физических упражнений у студентов КГ и ЭГ практически не отличались от таковых в городских условиях, $(\mathrm{p}>0,05)$.

Для определения уровня профессиональной подготовленности будущих учителей физической культуры использовались следующие критерии:

глубокое понимание физиологического механизма воздействия физических упражнений на организм занимающихся;

- выбор форм и средств физической культуры и спорта с учетом возрастных и других особенностей детей и подростков, а также условий проведения летнего оздоровительного лагеря;

- использование разнообразных форм физических упражнений и педагогического контроля выполнения двигательных заданий.

Критерии оценки (по пятибалльной системе):

5 баллов - знание механизма воздействия физических упражнений на организм; сформированность навыков использования естественных факторов природы при организации и проведении физкультурно-спортивной деятельности детей в летнем лагере; использование педагогического контроля качества выполнения двигательных заданий;

4 балла - понимание сущности физических упражнений и их влияния на организм; умение использовать особенности летнего оздоровительного лагеря в физкультурно-спортивной работе; проявление творческого подхода при проведении занятий; 
3 балла - проведение различных форм физкультурно-спортивной деятельности с использованием педагогических методов контроля;

2 балла - организация физкультурно-оздоровительной и спортивно-массовой деятельности без учета оздоровительной и эстетической функций физической культуры и спорта;

1 балл - непонимание структурного содержания физических упражнений, значимости их усвоения и рациональной техники, особенностей проведения в летнем оздоровительном лагере.

В КГ учебные занятия проводились в соответствии с учебным планом; в ЭГ использовалась разработанная нами методика совершенствования профессиональной подготовки будущих учителей на основе реализации оздоровительной и эстетической функций физической культуры и спорта. После окончания педагогического эксперимента было проведено повторное тестирование уровня профессиональной подготовки будущих учителей с использованием тех же критериев оценки, которые выставлялись экспертной комиссией из числа квалифицированных преподавателей факультета физической культуры и спорта. Анализ полученных результатов показал, что их улучшение произошло в обеих группах - КГ и ЭГ, с явным преимуществом студентов ЭГ. Так, при исходных данных понимания физиологического механизма воздействия физических упражнений на организм в КГ $2,81 \pm 0,24$ балла, к окончанию педагогического эксперимента показатели улучшились до $3,01 \pm 0,18$ балла, (p>0,05); в ЭГ, соответственно, при исходных данных $2,79 \pm 0,21$ балла, к завершению педагогического эксперимента результаты возросли до $3,77 \pm 0,24$ балла, $(\mathrm{p}<0,05)$. В КГ, при исходных данных сформированности навыков использования разнообразных форм и средств физической культуры и спорта с учетом особенностей условий проведения летнего оздоровительного лагеря 2,72 $\pm 0,19$ балла, к окончанию педагогического эксперимента показатели улучшились до $2,99 \pm 0,20$ балла, $(\mathrm{p}>0,05) ; \quad$ в $Э Г$, соответственно, при исходных данных $2,73 \pm 0,16$ балла, к завершению педагогического эксперимента результаты

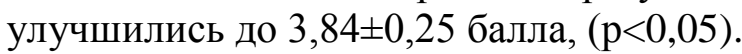

\section{ЗАКЛЮЧЕНИЕ}

Таким образом, результаты педагогического эксперимента показали, что уровень профессиональной подготовки будущих учителей физической культуры определяется организацией разнообразных видов педагогической деятельности с учетом условий их проведения: организации процесса физического воспитания учащихся общеобразовательной школы в условиях летнего оздоровительного лагеря, в туристическом походе и т.д. Такой подход обеспечивает более глубокое изучение особенностей организации физического воспитания и спорта с учетом различных видов и форм педагогической деятельности; функций физической культуры и спорта: образовательной, оздоровительной, воспитательной, эстетической, развивающей. Эффективность физической культуры и спорта, их воздействие на детей и подростков в значительной мере определяются уровнем профессиональной подготовки учителя. Это учитывается при организации деятельности преподавателей факультета физической культуры и спорта педагогических вузов по обеспечению теоретической, методической и практической подготовки студентов. Применение методики совершенствования профессиональной подготовки будущих учителей на основе реализации оздоровительной и эстетической функции физической культуры и спорта показало свою эффективность в подготовке студентов к организации физического воспитания в летнем оздоровительном лагере.

\section{Список литературы}

1. Бальсевич В.К. Здоровьесберегающая функция образования. Образовательная политика. 2007; 6: 4-9. 
2. Захаров С.И. Совершенствование физического воспитания школьников в свете современных концептуальных подходов. «Физическая культура и детско-юношеский спорт»: Материаль II международной научнопрактической конференщии. Якутск. 2008: 73-76.

3. Костюнина Л.И., Шакурова Л.Ф. Значимость педагогической практики в детских оздоровительных лагерях для повышения профессиональной подготовки будущего учителя. Казанская наука. 2014; 12: 216-218.

4. Кузнецова 3.М. Чернова Н.А. Реализация программы формирования личностных качеств студентов в образовательной деятельности как одна из реальных предпосылок обновления содержания подготовки специалистов в системе высшего образования (на примере студентов Пов. ГАФКСиТ по специальности «Сервис и туризм»). Педагогикопсихологические и медико-биологические проблемы физической культуры и спорта. 2011; 1(18): 143149. URL: http://www.journalscience.org/ru/article/378.html.

5. Лубышева Л.И. Спортивная культура в школе. М.: НИЦ «Теория и практика физической культуры и спорта». 2006: 174.

6. Назаренко Л.Д. Оздоровительные основы физических упражнений. М.: Изд-во ВЛАДОС-ПРЕСС. 2003: 240.

7. Назаренко Л.Д. Спорт как культурологический феномен современного общества. Феномен спортивной культуры в аспекте философского, исторического и сочиально-педагогического анализа: научнометодические материаль и докладьл «Круглого стола». Москва. 2014; 21 марта.

8. Назаренко Л.Д., Анисимова Е.А. Воспитание в спорте. Теория и практика физической культуры и спорта. М. 2015: 80.

9. Неверкович С.Д. Педагогика физической культуры и спорта: учебник для студентов высших учебных заведений, обучающихся по спещиальности «Физическая культура и спорт». М.: Академия. 2010: 329.

10. Столяров В.И., Бальсевич В.К., Моченов В.П., Лубышева Л.И. Модернизация физического воспитания в общеобразовательной школе. М.: НИЦ «Теория и практика физической культуры». 2009: 320.

11. Назаренко Л.Д. Физическая культура и спорт - средство физического, духовнонравственного развития школьников и учащейся молодежи. Ульяновск. 2012: 191.

12. Шакурова Л.Ф. Реализация здоровьеформирующей функции физического воспитания в условиях загородного летнего оздоровительного лагеря. Педагогикопсихологические и медико-биологические проблемь физической культуры и спорта. 2017; 3: 152-160. URL: http://www.journalscience.org/ru/article/862.html. DOI 10/4526/03 -2017 -246 .
13. Kuznetsova Z., Kuznetsov A., Mutaeva I., Khalikov G., Zakharova A., 2015. Athletes training based on a complex assessment of functional state. In Proceedings of the $3^{\text {rd }}$ International Congress on Sport Sciences Research and Technology support. SCITEPRESS. P. 156-160 (Scopus).

14. Kuznetsov A., Mutaeva I., Kuznetsova Z., 2017. Diagnostics of Functional State and Reserve Capacity of young Athletes' Organism. In Proceedings of the $5^{\text {th }}$ International Congress on Sport Sciences Research and Technology support. SCITEPRESS. P. 111-115 (Scopus).

\section{References}

1. Balsevich V.K. Health protecting function of education. Obrazovatel'naya politika. 2007; 6: 4-9 [In Russ.].

2. Zakharov S.I. Physical upbringing of schoolchildren development in terms of modern conceptual approaches. "Fizicheskaya kul'tura I detsko-yunosheskij sport”: materialy II Mezhdunarodnoj nauchno-prakticheskoj konferencii ["Physical culture and sport for children and teenagers": Materials of the IInd International scientificpractical conference]. Yakutsk. 2008: 73-76.

3. Kostyunina L.I., Shakurova L.F. The importance of pedagogical practice at health camps for children for professional training of a future teacher improvement. Kazanskaya nauka = Kazan science. 2014; 12: 216-218 [In Russ., In Engl.].

4. Kuznetsova Z.M. The program realization of students' personal qualities formation in educational activity as one of real preconditions for content renewal of specialists training in the system of higher education (by the example of students of Povolzhskaya State Academy of Physical Culture, Sport and Tourism according to "Service and tourism" specialty). Pedagogiko-psihologicheskie I mediko-biologicheskie problemy fizicheskoj kul'tury I sporta = Pedagogicopsychological and medico-biological problems of physical culture and sport. 2011; 1(18): 143-149. URL: http://www.journal-science.org/ru/article/378.html [In Russ., In Engl.].

5. Lubysheva L.I. Sportivnaya kul'tura $v$ shkole [Sport culture at school]. Moscow: Scientific Research Center "Theory and practice of physical culture and sport". 2006: 174.

6. Nazarenko L.D. Ozdorovitel'nye osnovy fizicheskih uprazhnenij [Health improving basis of physical exercises]. Moscow: VLADOS-PRESS publishing house. 2003: 240.

7. Nazarenko L.D. Sport as culturological phenomenon of modern society. Fenomen sportivnoj kul'tury $v$ aspekte filosofskogo, istoricheskogo I social'no-pedagogicheskogo analiza: nauchnometodicheskie materialy I doklady "Kruglogo stola" [Phenomenon of sports culture in the aspect of philosophical, historical and social-pedagogical analysis: scientific-methodical materials and reports of “A round-table discussion". Moscow. 2014; March, 21.

8. Nazarenko L.D., Anisimova E.A. Upbringing in sport. Teoriya I praktika fizicheskoj 
kul'tury I sporta [Theory and practice of physical culture and sport]. Moscow. 2015: 80.

9. Neverkovich S.D. Pedagogika fizicheskoj kul'tury I sporta: uchebnik dlya studentov vysshih uchebnyh zavedenij, obuchayuchihsya po special'nosti "Fizicheskaya kul'tura I sport" [Pedagogics of physical culture and sport: textbook for students of higher educational establishments, who study according to "Physical culture and sport" specialty]. Moscow: Academy. 2010: 329.

10. Stolyarov V.I., Balsevich V.K., Mochenov V.P., Lubysheva L.I. Modernizaciya fizicheskogo vospitaniya $v$ obcheobrazovatel'noj shkole [Physical upbringing modernization at comprehensive school]. Moscow: Scientific Research Center "Theory and practice of physical culture". 2009: 320.

11. Nazarenko L.D. Fizicheskayakul'tura I sport - sredstvo fizicheskogo, duhovno-nravstvennogo razvitiya shkol'nikov I uchachejsya molodezhi [Physical culture and sport as the means of physical, spiritual-moral development of schoolchildren and students]. Ulyanovsk. 2012: 191.
12. Shakurova L.F. Health forming function of physical upbringing realization in terms of country summer health camp. Pedagogiko-psihologicheskie I mediko-biologicheskie problemy fizicheskoj kul'tury I sporta = Pedagogico-psychological and medicobiological problems of physical culture and sport. 2017; 3: 152-160. URL: http://www.journalscience.org/ru/article/862.html. DOI: 10/4526/03 -2017 $-246$.

13. Kuznetsova Z., Kuznetsov A., Mutaeva I., Khalikov G., Zakharova A., 2015. Athletes training based on a complex assessment of functional state. In Proceedings of the $3^{\text {rd }}$ International Congress on Sport Sciences Research and Technology support. SCITEPRESS. P. 156-160 (Scopus).

14. Kuznetsov A., Mutaeva I., Kuznetsova Z., 2017. Diagnostics of Functional State and Reserve Capacity of young Athletes' Organism. In Proceedings of the $5^{\text {th }}$ International Congress on Sport Sciences Research and Technology support. SCITEPRESS. P. 111-115 (Scopus).

\title{
Подано: 24.05 .2018
}

Шакурова Лилия Фагимовна - старший преподаватель, Федеральное государственное бюджетное образовательное учреждение высшего образования «Ульяновский государственный педагогический университет имени И.Н. Ульянова», 432700, Россия, 2. Ульяновск, Площадь 100-летия со дня рождения В.И. Ленина, дом 4

DOI 10.14526/02_2018_328

УДК 796.2

\section{ИЗМЕНЕНИЕ АНТРОПОМЕТРИЧЕСКИХ ПОКАЗАТЕЛЕЙ В ВОЗРАСТНОМ ПЕРИОДЕ 50-55 ЛЕТ НА ОСНОВЕ ИСПОЛЬЗОВАНИЯ ЭТНИЧЕСКИХ ИГР КЫРГЫЗОВ В УСЛОВИЯХ СРЕДНЕГОРЬЯ}

\author{
Абдырахманова Д.О. ${ }^{1}$, Тыналиева Б.К. ${ }^{2}$, Абдырахманов Б.А. ${ }^{3}$, Болжирова Э.Ш. ${ }^{3}$ \\ ${ }^{1}$ Высшая школа физической культуры и спорта Кыргызско-Турецүкий Университет «Манас», \\ Кьргызстан, г.Бишкек, jipard@таil.ru \\ ${ }^{2}$ Кыргызская государственная медииинская академия им. И.К. Ахунбаева \\ 720020, Кыргызстан, г. Бишкек, ул. Ахунбаева, дом 92, tynalievab@таil.ru \\ ${ }^{3}$ Кыргыззская государственная академия физической культуры и спорта \\ Кыргызстан, г.Бишкек, abdybekzhan@gmail.com,emiliya0810@mail.ru
}

Аннотация. В работе рассматриваются вопросы влияния занятий этническими играми кыргызов на изменение антропометрических показателей взросльх людей 50-55 лет. Обследовано 32 взрослых человека. Первая группа состояла из 16 взрослых, занимаюшихся этническими играми; во второй группе - 16 взросльх, не занимающихся этническими 